\title{
Solder Fume Exposure
}

National Cancer Institute

\section{Source}

National Cancer Institute. Solder Fume Exposure. NCI Thesaurus. Code C156871.

Environmental, occupational, or consumer-based exposure to vaporized materials during the soldering process. 